\title{
Social Media Research: A Review of Academic Research and Future Research Directions
}

\author{
Ashir Ahmed \\ Swinburne University of Technology \\ Australia \\ azahmed@swin.edu.au \\ Helana Scheepers \\ Swinburne University of Technology \\ Australia \\ hscheepers@swin.edu.au \\ Rosemary Stockdale \\ Swinburne University of Technology \\ Australia \\ rstockdale@swin.edu.au
}

\begin{abstract}
Research into social media has proliferated significantly over the last few years. However, the majority of papers published in this domain lack rigorous theoretical underpinning. This paper provides a report on a systematic literature search of social media research papers in major Information Systems (IS) outlets including journals and conferences from January 2009 to January 2013. The survey of literature indicates that there is a continuous increase in the number of social media research articles published over the last few years. Furthermore, we found that the majority of papers were data driven and not theory driven and a greater number of papers were published in conferences than in journals. In summary, we suggest that research into social media has been emerging over a period of time and there are numerous opportunities for researchers to conduct rigorous studies in this area. Moreover, it is anticipated that the review presented in this paper will be a good resource for future research into social media and will stimulate further interest in this area.
\end{abstract}

Keywords: Social Media, Social Media Research, Information Systems 


\section{Introduction}

Social media technologies have caught the public interest in a way that few technologies have achieved in recent years. There is a growing field of research into the uses of social media applications and the impact they have on organisations and individuals. Despite the expanding body of literature, research into social media is still in its infancy. The term itself remains imprecise and there is, as yet, no common definition available (Xianga et al. 2010). According to the generalist source of Wikipedia, 'social media includes web - and mobile - based technologies which are used to turn communication into interactive dialogue among organizations, communities, and individuals'. In his 'Social Media Bible', Safko (2010) takes the very broad perspective of 'social media is the media we use to be social' (p.3). Although this short definition describes the purpose of social media, Safko acknowledges that it does not include the tactics of hundreds of tools and technologies that are available to connect users of social media (Safko 2010). An earlier attempt to define social media identifies the key factor of user generated content: 'social media can be generally understood as Internet-based applications that carry consumer-generated content which encompasses media impressions created by consumers, typically informed by relevant experience, and archived or shared online for easy access by other impressionable consumers' (Blackshaw 2006). This includes a variety of applications in the technical sense, which allow consumers to 'post', 'tag', 'digg', or 'blog', and so forth, on the Internet. The content generated by these social media applications includes a variety of new and emerging sources of online information that are created, initiated, circulated, and used by consumers with the intent of educating each other about products, brands, services and issues. In contrast to content provided by marketers and suppliers, social media content is produced by consumers to be shared among themselves (Xianga et al. 2010). A significant advance in defining social media is the highly cited paper by Kaplan and Haenlein (2010) and this study takes their perspective of social media as 'a group of Internet-based applications that build on the ideological and technological foundations of Web 2.0, and that allow the creation and exchange of User Generated content'.

Research into social media is widespread across many discipline areas. Coupled with the deluge of newspaper articles and business reports, the current landscape of published information is both overwhelming and unstructured. In order to separate the 'hype from the hope' (Feller et al. 2006), we have carried out an examination of the IS literature to distinguish research trends from the hyperbole of the merely anecdotal. This paper analyses current trends in social media research within the academic area of IS. Specifically we are attempting to answer the following research questions:

1. What types of social media papers (in terms of background paradigm, research method, data driven vs theory driven and choice of social media applications) are published in leading IS research outlets?

2. What are the theoretical bases for social media research?

The findings will contribute to consolidating the early work in this important area to provide insights into theories used as well as paradigmatic and methodological trends. It will also enable articulation of what needs to be done, clarifying areas for future research. The paper is structured as follows. First, we discuss the value of reviewing publications in a specific field. Second, we describe the methodology employed for this study. This is followed by an analysis of the results of the study.

\section{Rationale for the Classification of Research Publications in Social Media}

There have been a number of studies aimed at consolidating IS research to provide overviews of research areas (Dibbern et al. 
2004) or, more usually, of journal publication trends (Chen et al. 2004; Mingers 2003). These reviews have addressed different aspects of IS publications such as identifying top journals (Chen et al. 2004), analysing articles in AIS (Association of Information Systems) journals (Liu et al. 2011), examining the incidence of mixed methods or concentrating on a specific research topic such as open source software(Feller et al. 2006) or outsourcing (Dibbern et al. 2004). Such papers examine the paradigms and methodologies used by researchers and provide important insights into the nature of the discipline, geographic and paradigmatic trends as well as how research is evolving and changing over time. Scornavacca, Barnes, and Huff (2005) indicate that this is an acceptable method for understanding what research is being conducted in a specific research field. The importance of reviewing literature is further emphasised by Webster and Watson (2002) who argue that: 'An effective review creates a firm foundation for advancing knowledge' and 'uncovers areas where research is needed' ( $p$. xiii).

In our examination of social media research, we have drawn on the criteria used in previous studies to shape our analysis of the peer reviewed papers we found. Mingers (2003), Chen and Hirschheim (2004) and Liu and Myers (2011) propose a number of criteria to classify IS papers. They analyse the identified literature based on background paradigm (positivist vs. interpretive), research method (qualitative vs. quantitative), nomothetic vs. ideographic, intensive vs. extensive, cross-sectional vs. Iongitudinal, empirical vs. non-empirical and theory vs. data driven. Taking the broad and unique nature of social media research, where it often diverges from mainstream IS, it is logical to adapt the criteria used in mainstream IS to cater to the unique characteristics of social media research. Hence, the classifications of papers in this study are; background paradigm (positivist vs. interpretive), research method (qualitative vs. quantitative), and data vs. theory driven approach. Due to the novel nature of social media research we have included another category that addresses the type of social media application being studied. The following section explains these classifications and discusses their relevance to this research.

\section{Background Paradigm}

According to Mingers (2003), research methods develop within a particular paradigm, but the relationship between paradigm and research method is far from clear. However, a general consensus is found in categorizing the background paradigm into positivist and interpretive to understand the general orientation of a research method and its basic assumptions. Careful review of relevant literature suggests that positivist articles were identified on the basis of evidence of formal propositions, quantifiable measures of variables, the use of hypothesis testing, and the drawing of inferences about phenomena from sample to a stated population.

The criteria for selecting interpretive articles are that the articles should not involve any of these positivist indicators (Chen et al. 2004). Moreover, interpretive articles should provide evidence of a non-deterministic perspective, intent to increase understanding of the phenomena within a specific cultural and contextual setting, and an examination of the phenomena and the setting from the perspective of participants (Walsham 1995).

Critical research is often overlooked in IS research (Myers et al. 2011) and is mentioned as the 'missing paradigm' by (Chen et al. 2004). While there has recently been a rise in interest in the paradigm, we have found no papers that use a critical research approach in social media papers.

\section{Research Method}

The literature suggests around 50 different research terms to describe research methods although the majority of these terms refer to the same thing. For instance, case study vs. interviews and surveys vs. questionnaire can be seen to represent the same methods. Generally, quantitative vs. 
qualitative is used as a common distinction between two main types of research methods. However, Yin (1994) argues that this distinction properly applies to the nature of 'data' rather than the research method. For instance, a particular type of research method like case study, questionnaires, or interviews may generate both types of data and there is a tendency to mix the two as they are mutually informing (Bryman 2001). We take Chen and Hirschheim's (2004) criterion for categorizing research methods into the two main categories of qualitative and quantitative. They note that there can be some confusion in categorization as the former addresses understanding behind the factors in question while the latter analyses the relationship between the factors. Therefore the distinction here is based on whether statistical or numerical approaches are employed in the collection and analysis of data. Further to the above argument, there is a possibility that research could use both of these research methods (mixed research method) in different stages of the study. In such cases, we include them in both types of research methods.

\section{Data Driven vs. Theory Driven}

Data driven research refers to a study where the data are approached without specific theories or hypothesis. In contrast, theory driven research refers to studies where data are seen as a way of confirming or disconfirming existing theory. Qualitative and quantitative data could be used in either of these approaches. Anecdotally, current trends observed in social media research are held to favour the former approach and therefore this aspect (data/theory driven) of categorization is of some importance for determining the nature of this field of research. While each of these approaches makes different contributions to the research community, Chen and Hirschheim (2004) suggest that as a discipline becomes more mature, one might expect theory-testing to outweigh theory-building efforts. Overall, the comparison between these approaches serves as a meaningful indication of the progress made in the field.

\section{Social Media Applications}

The term social media is often used interchangeably with social networks, social networking, Enterprise 2.0 and Web 2.0 despite a range of distinctions in the literature (Boyd et al. 2008; Kaplan et al. 2010). We have not distinguished between social networking tools such as Facebook and Web 2.0 applications such as YouTube. With their growing popularity the wide range of social media applications (also referred to as social media tools) available is steadily increasing. These tools offer various features (such as to share texts, videos and pictures) to their users and facilitate their ability to 'socialize' with others. We have identified by name the social media applications that appear in more than one research study, such as the common tools Facebook, Twitter and LinkedIn. Social media applications that appeared in only one article are categorized under 'Others' in our analysis.

\section{Methodology ${ }^{1}$}

The relative newness of the research domain of social media means that many existing papers are published in journals and proceedings that have short lead times for publication. While there are a number of calls for papers in major journals currently in process that will enhance the research field with more robust research, much of the existing literature appears in conference proceedings. Although conference proceedings are rarely considered for this type of consolidation study, they are a common outlet for new and growing areas of research such as social media and provide insights into early trends. We have therefore included conference papers in our analysis. The conferences included and reasons for inclusion:

- International Conference on Information Systems (ICIS). A premier Information systems conference,

\footnotetext{
${ }^{1}$ Please contact the authors should you require more details on research papers included in this study
} 
- European Conference on Information Systems (ECIS). A premier European information systems conference

- Pacific Asia Conference on Information Systems (PACIS). A premier Asia Pacific information systems conference,

- Americas Conference on Information Systems (AMCIS). A premier Americas information systems conference,

- Hawaii International Conference on System Sciences (HICCS). The longest running scientific conference.

The general methodology employed in this research follows that of Mingers (2003) and Ngai et al. (2008). A range of research databases were used for identifying potential social media research papers: Computers and Applied Science Complete, Scopus, Web of Knowledge and Expanded Academic ASAP. These research databases were chosen as they included all the highly ranked journal publications such as: European Journal of Information Systems (EJIS), Information Systems Journal (ISJ), Information Systems Research (ISR), Information Technology and People (ITP), Journal of the Association for Information Systems (JAIS), Journal of Information Technology (JIT), Journal of Management Information Systems (JMIS), and MIS Quarterly.

The following search process was used:

1. The databases identified above were searched using various combinations of the terms such as 'social media', 'social networking' and 'Web 2.0' in the title, keywords or abstract of the paper. The conference papers were accessed through Google Scholar and through the AIS repository using the same terms.

2. All papers identified in the step above were downloaded. The abstract of the papers were read and a decision was made to include a paper based on the following criteria:

a. the relevance of the paper to the topic being studied, b. clear description of the background paradigm,

c. clear description of the research method,

d. clear description of the theory/data driven approach and

e. clear description of the use of social media application.

3. Papers that failed to meet the above (step 2) criteria were excluded

4. Papers that were about technical aspects of social media were excluded.

5. In all cases where there was any uncertainty about the nature and/or relevance of the article, the original article was read in full.

6. As a result of steps 3 and 4 , the list of short listed articles was reduced significantly

7. All papers identified were recorded in Endnote (a bibliography management system).

Analysis of the data was then performed using our classifications of background paradigm (positivist vs. interpretive), research method (qualitative vs. quantitative), data vs. theory driven approach and type of social media application. The analysis of the papers was recorded in an Excel spread sheet.

Although the databases identified a number of papers, only those that were clearly identified as IS were included. This led to the restriction of journal papers to those found in the four leading journals that could be classified as clearly in IS. Articles from nonIS sources were not included. The four journals are highly rated IS publications ( $A^{*}$ and $A$ journals in the Australian ERA rankings) and the five conferences are all AIS listed. A total of 194 papers were identified and analysed following the process above. All of the conference and journal papers were examined individually by two of the authors. Differences in identification and classification were referred to the third author for clarification who read the paper in full and consulted with the other two authors 
until consensus was reached. The period of study is from January 2009 to January 2013. Although the period of four years selected for this research is not extensive it is significant in terms of various developments made on both the theoretical and practical sides of social media. For instance (Curtis 2013):

2009:

- In 2009, Facebook ranked as the most-used social network worldwide with more than 200 million. The site's traffic was twice that of MySpace.

- In 2009, "Unfriend" was the New Oxford American Dictionary word of the year.

- It is estimated that a quarter of the Earth's population used the Internet.

2010:

- No common definition of social media was yet available in IS research (Xianga et al. 2010).

- A significant advance in defining social media is the highly cited paper published by Kaplan and Haenlein (2010) that has been cited nearly 2000 times.

- Facebook's rapid growth moved it above 400 million users.

- To compete with Facebook and Twitter, Google launched Buzz, a social networking site integrated with the company's Gmail. It was reported that in the first week, millions of Gmail users created 9 million posts.

- It was estimated the population of Internet users was 1.97 billion. That was almost 30 per cent of the global population.

2011:

- Social media were accessible from virtually anywhere and had become an integral part of our daily lives with more than 550 million people on Facebook, 65 million tweets sent through Twitter each day, and 2 billion video views every day on YouTube. LinkedIn has 90 million professional users.
- Social media commerce was on the rise along with mobile social media via smart phones and tablet computers.

- It was estimated Internet users would double by 2015 to a global total of some four billion users, or nearly 60 per cent of the Earth's population.

2012:

- Ever more people are connecting to the Internet for longer periods of time. Some 2 billion people around the world use the Internet and social media, while 213 million Americans use the Internet via computers while 52 million uses the Web via smart phone and 55 million use it via tablets. People also connect to the Internet via handheld music players, game consoles, Internet-enabled TVs and e-readers.

- Social media has come of age with more people using smart phones and tables to access social networks. New sites emerge and catch on. The top ten social networks are Facebook, Blogger, Twitter, Wordpress, LinkedIn, Pinterest, Google+, Tumblr, MySpace and Wikia.

- More than half of adults 25-34 years of age use social media at the office. Almost a third of young adults 18-24 years of age use social media in the bathroom. All use social networks to stay connected with acquaintances, be informed and be amused.

- Advertisers look to social 'likes' to enhance brand visibility.

- Facebook reached a billion users in 2012.

- YouTube has more than 800 million users each month with more than 1 trillion views per year or around 140 views for every person on Earth.

\section{Analysis of Results}

The purpose of analysing these articles was to study various trends such as choice of background paradigm, research method, 
theories and various applications used in social media research. The analysis of data is aimed to provide guidelines for the pursuit of future research on social media and its applications by explaining the chronological growth of social media over the last few years, the challenging areas of social media theory and application, and major issues surrounding various categorization criteria mentioned above.

We begin with an overview of the papers included in this study. Out of the 194 papers identified only 26 papers were published in journals whereas the remaining 168papers were published in conferences during this period. Figure 1 depicts an overall view of the number of articles selected from the nine sources (including four journals and five conferences) along with their percentages against total number of papers published in these outlets. Data provided in Figure 1 highlight the fact that IS conferences are the most popular venues to publish social media research as compared to their journal counterparts over the last four years.

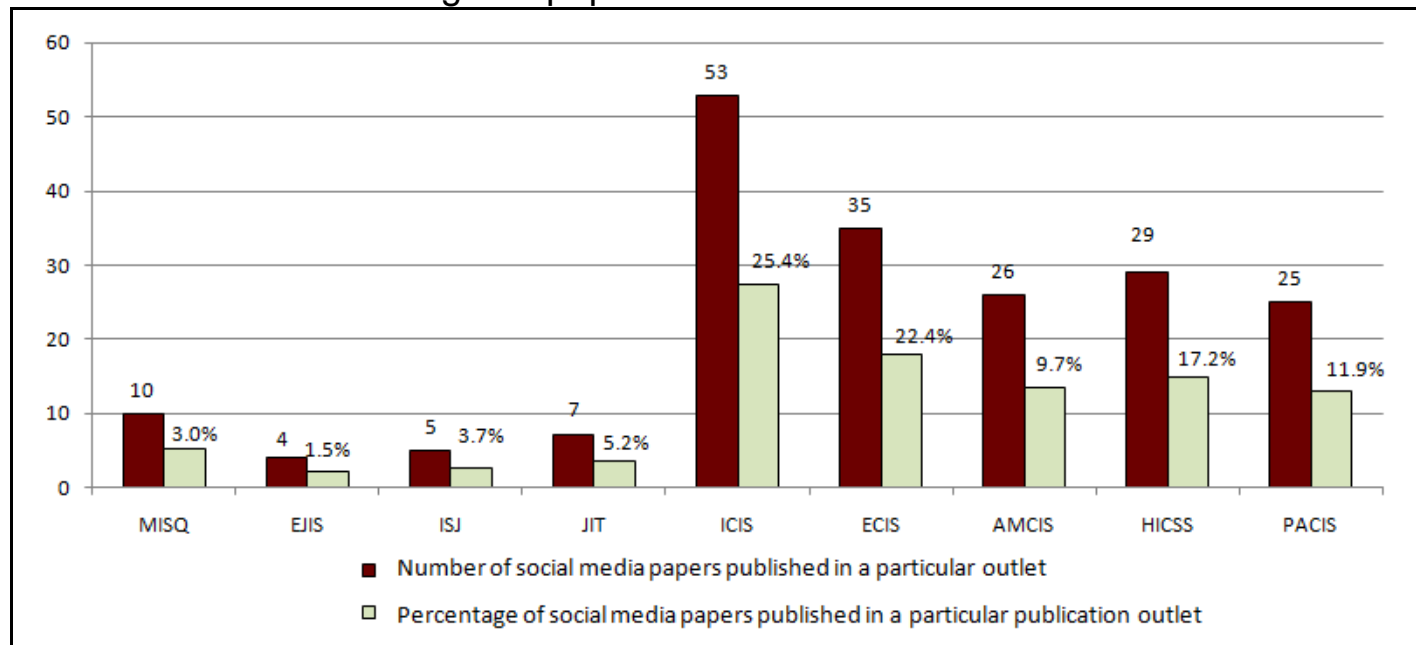

Figure 1 - Number and Percentage of Articles Published in Selected Journals and Conferences during Jan 2009-Jan 2013

Analysis of the selected articles indicates a steady increase in the number of publications on social media research. During the first three years (from 2009 to 2011) there is approximately 4\% yearly increase in the number of publications whereas in the last year (2012) there is a significant increase of more than $20 \%$ (approximately) in the publications of social media research. Figure 2 below shows the increases in publications on social media from January 2009 to January 2013. Figure 2 indicates the number of publications per year and also the percentage of social media research papers compared to the total number of papers published for that year. 


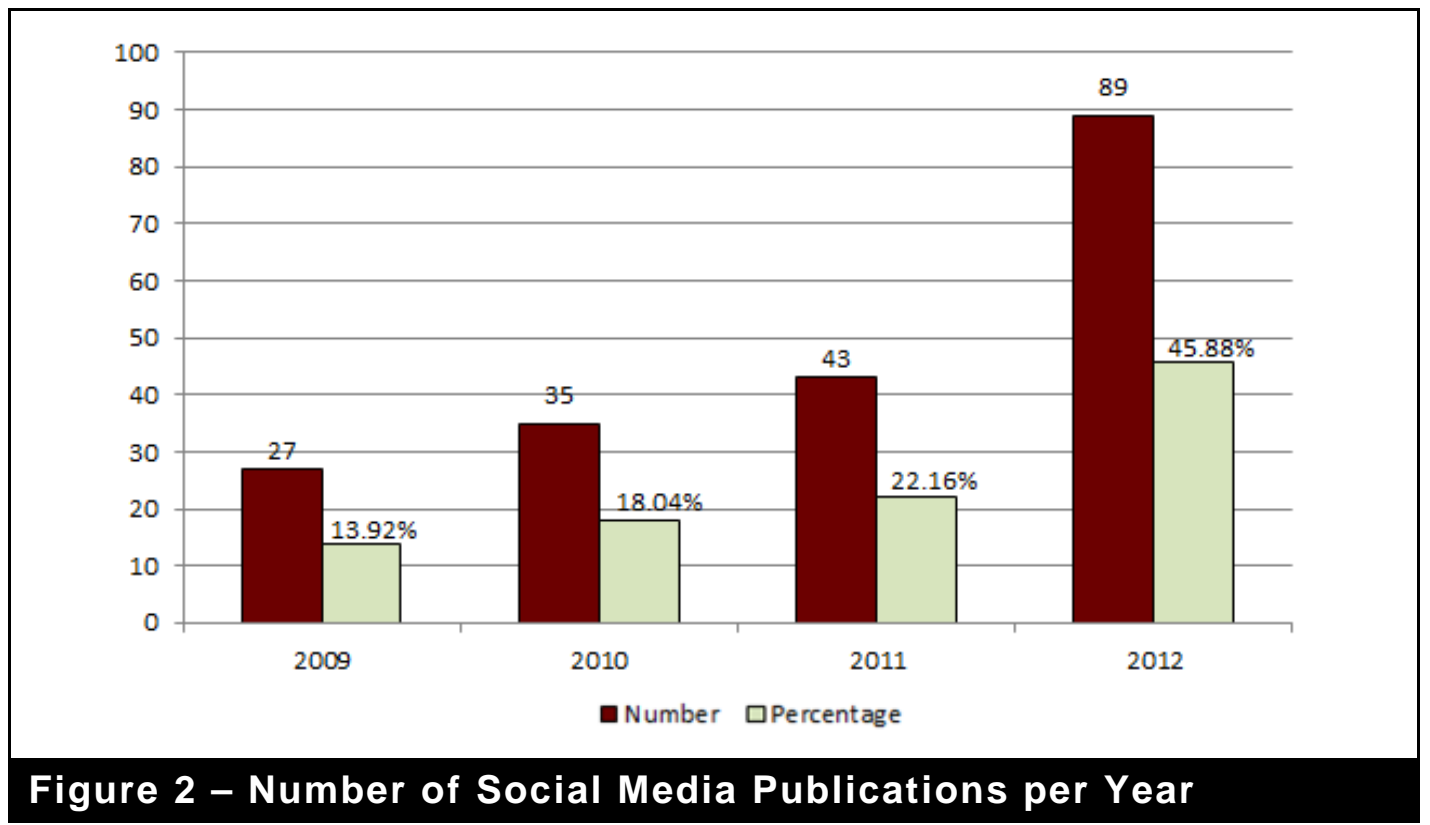

\section{Distribution of Articles by Backg- round Paradigm}

In the context of the background paradigm, positivist versus interpretive, the majority of articles included in the study are positivist. A total of $141(72.68 \%)$ articles employ a positivist paradigm whereas only $53(27.32 \%)$ articles were interpretive. The findings are illustrated in Figure 3. The majority of the examined social media research papers give the forms of data collection including internally or externally published data, direct observations, simulation, consultancy reports, recording or measurement. The data are generally quantitative and few articles employ data collection methods such as ethnography, grounded theory, participant observation or qualitative content analysis.

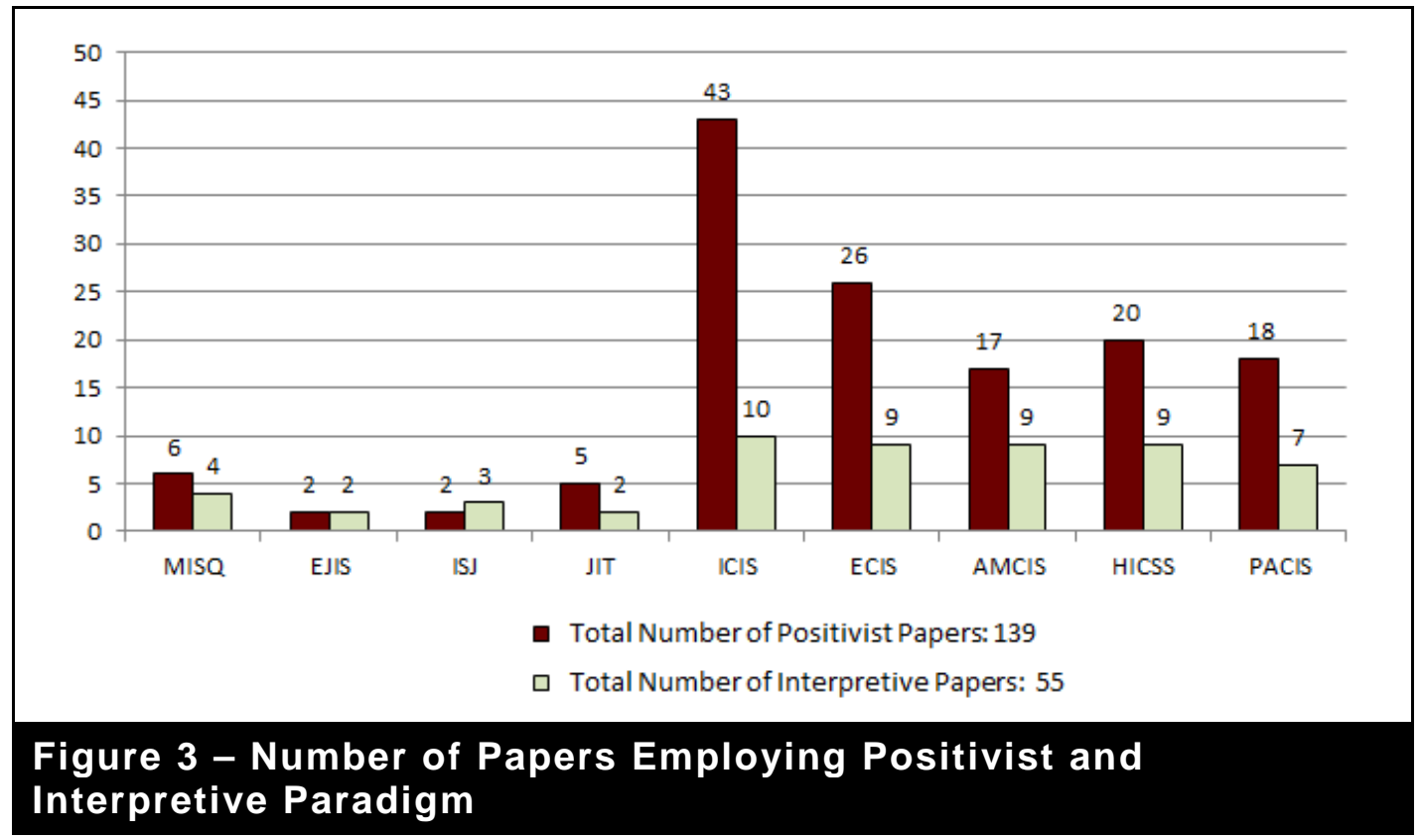

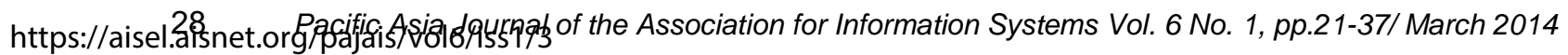




\section{Distribution of Articles by Research Method}

In this section, we analyse the selected articles and identify the usage of different research methods. A total of 194 articles were categorized into two broader categories of research methods; qualitative and quantitative. Where a paper records multiple methods (also referred as a mixedmethod approach), each method is counted in both categories and depicted as $\left(^{*}\right)$ in Figure 4 below. The analysis process clearly shows a high proportion of papers (62.41\%) using quantitative methods where Statistical tests are used for the analysis of social media data. The majority of these papers employed surveys, structured interviews, observations, and reviews of records or documents for numeric information. On the other hand only $37.59 \%$ papers used qualitative methods which include focus groups, in-depth interviews, case studies and reviews of documents for types of themes.

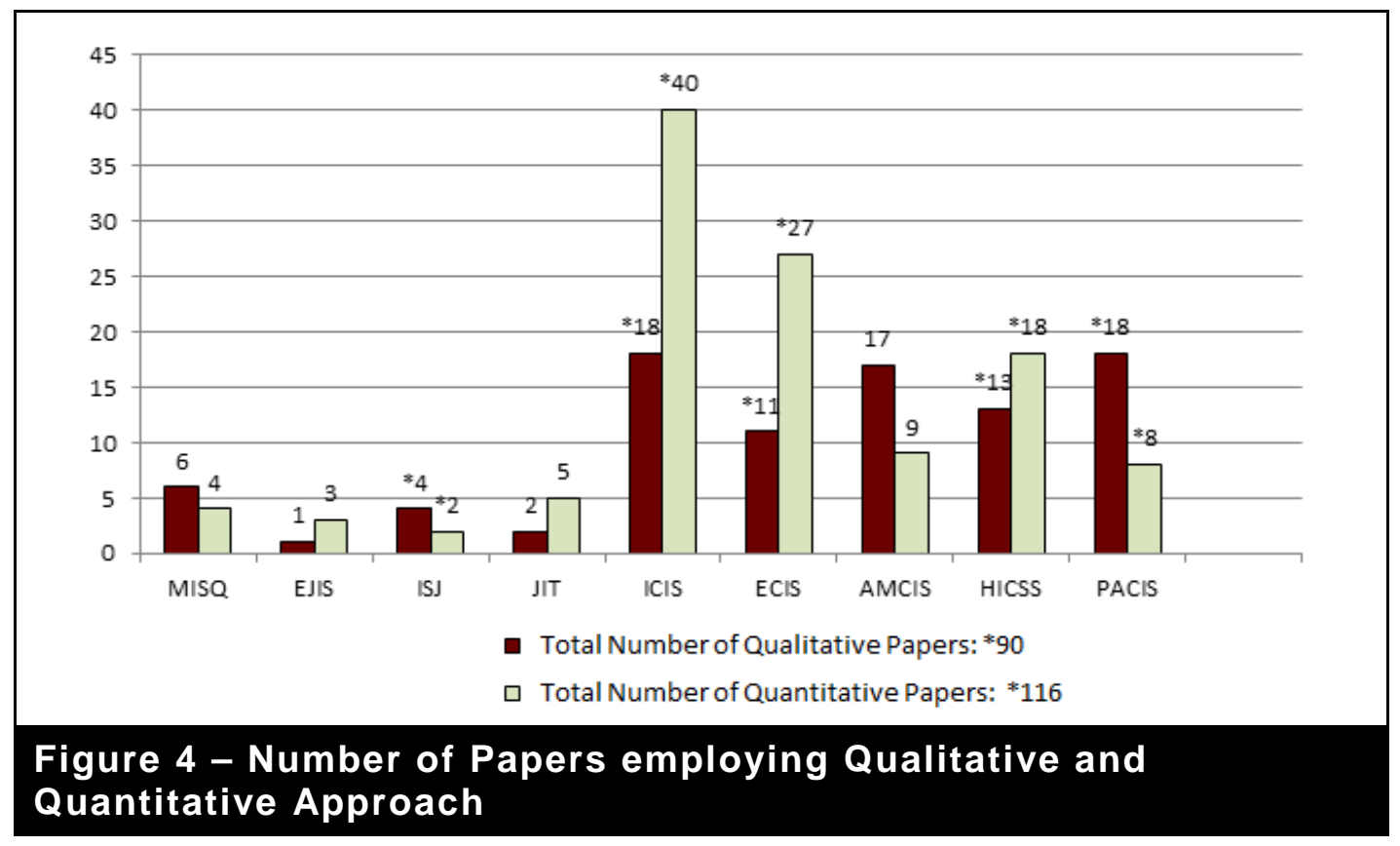

\section{Distribution of Articles by Theory Driven vs Data Driven}

A general perception, albeit anecdotal, of social media research is that it often lacks theoretical underpinnings. Such perceptions are supported by the analysis of papers included in this study. It was found that 125 (64.43\%) papers used a data driven (empirical) approach whereas only 69 $(35.56 \%)$ can be considered to be theory driven. This analysis shows that the vast majority of articles (64.43\%) present empirical findings derived from a data driven approach where the data are approached without specific theories or hypotheses. The following figure (Figure 5 depicts) the number of papers employing theory driven and data driven approaches. 


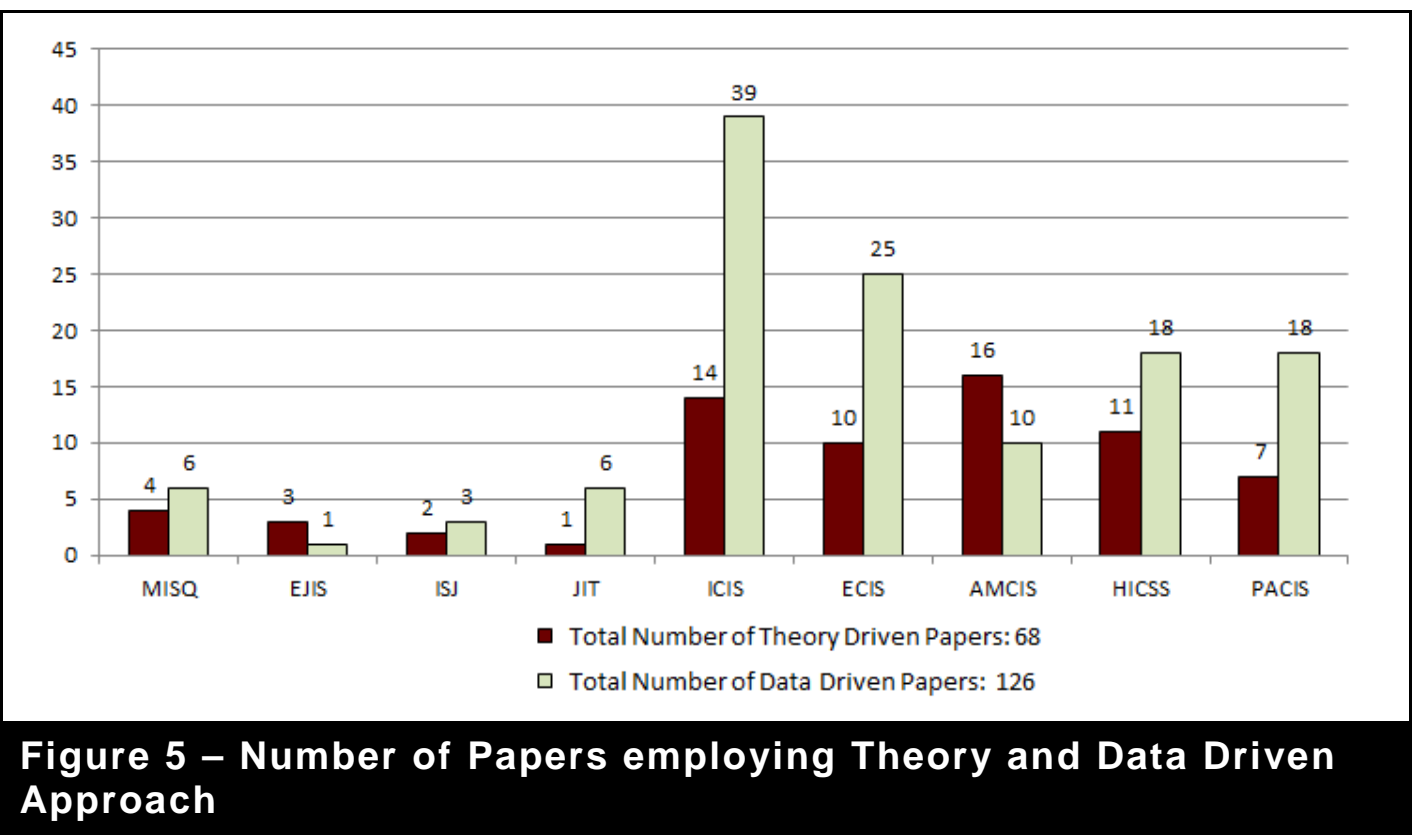

In addition to the number of theory driven and data driven articles (Figure 5), this study further identified the different theories, models or frameworks that are used in the articles under study. Analysis of the theories shows (Table 1 below) that 43 different theories, models or frameworks have been used in a total of 66 (theory driven) articles. Social capital was the most commonly used theory. Other than social capital theory, the theories of privacy calculus, online social network dependency, communities of practice, media richness theory, technology acceptance model and unified theory of acceptance and use of technology are used more than once whereas the remaining 36 theories, models or frameworks are used only once. 


\begin{tabular}{|c|c|c|c|}
\hline Theory Name & Occurrence & Theory Name & Occurrence \\
\hline Social capital theory & 12 & Theory of customer value & 1 \\
\hline Technology acceptance model & 5 & Theory of deceptive behaviour & 1 \\
\hline Communities of practice & 4 & Stages of growth model & 1 \\
\hline Media richness theory & 3 & $\begin{array}{l}\text { Theory of group identity and } \\
\text { interpersonal bonds }\end{array}$ & 1 \\
\hline Privacy calculus & 2 & $\begin{array}{l}\text { The broaden and build theory } \\
\text { of positive emotions }\end{array}$ & 1 \\
\hline $\begin{array}{c}\text { Unified theory of acceptance and } \\
\text { use of technology }\end{array}$ & 2 & Porter's five forces model & 1 \\
\hline Online social network dependency & 2 & Theory of social psychology & 1 \\
\hline $\begin{array}{c}\text { Communication privacy } \\
\text { management }\end{array}$ & 1 & Self-discrepancy theory & 1 \\
\hline Theory of intrinsic motivation & 1 & Communication theory & 1 \\
\hline Theory of planned behaviour & 1 & Social impact theory & 1 \\
\hline Grounded theory & 1 & Social influence theory & 1 \\
\hline Theory of functionalist motivations & 1 & $\begin{array}{c}\text { Theory of socio-emotional } \\
\text { selectivity }\end{array}$ & 1 \\
\hline Theory of reasoned action & 1 & Diffusion of innovation & 1 \\
\hline Social network & 1 & Theory of role identity & 1 \\
\hline Social identity theory & 1 & Social exchange & 1 \\
\hline Theory of critical mass & 1 & Media synchronicity & 1 \\
\hline $\begin{array}{c}\text { Decomposed theory of planned } \\
\text { behaviour }\end{array}$ & 1 & $\begin{array}{c}\text { Theory of action based } \\
\text { network }\end{array}$ & 1 \\
\hline Collective action theory & 1 & Social cognitive & 1 \\
\hline Network effect theory & 1 & Structural holes theory & 1 \\
\hline Theory of audience gatekeeping & 1 & Adaptive cognitive theory & 1 \\
\hline Boundary Theory & 1 & Cognitive emotion theory & 1 \\
\hline Theory of social presence & 1 & & \\
\hline \multicolumn{2}{|c|}{ Total Number of Theories Used } & \multicolumn{2}{|l|}{43} \\
\hline \multicolumn{2}{|c|}{ Total Number of Theory Driven Papers } & \multicolumn{2}{|l|}{66} \\
\hline
\end{tabular}

\section{Distribution of Articles by Social Media Applications}

In contrast to the categorization scheme suggested by Mingers (2003), this paper introduces the category of the particular social media applications that are the focus of each study. Social media applications are identified where there is more than 1 article focussing on a particular social media application. This results in the categorization of social media applications into four main categories including Twitter, Facebook, Second Life and Wikipedia. The more generic term 'blog' is also included as a named category as the analysis of blogs is relatively common, but few are named specifically. Social media applications that 
were identified in only one article are labelled as 'Others' and include Sinamicroblog, Tianya, CDSN blog, Prosper, Taobao.com, Paipai.com, MMOG Ocean Control, Habbo, Vkintakte.ru, Ireko, 1187.com, and Bittorrent. Moreover, the articles that did not mention any specific social media application but used a generic term such as 'social media' or 'social networking sites' are also labelled as 'Others'. It was found that Facebook was the most popular social media application for researchers and constitutes $30.60 \%$ of the studies whereas Twitter is the second most popular social media application (12.69\%). Figure 6 depicts the percentage of most commonly used social media applications in research.

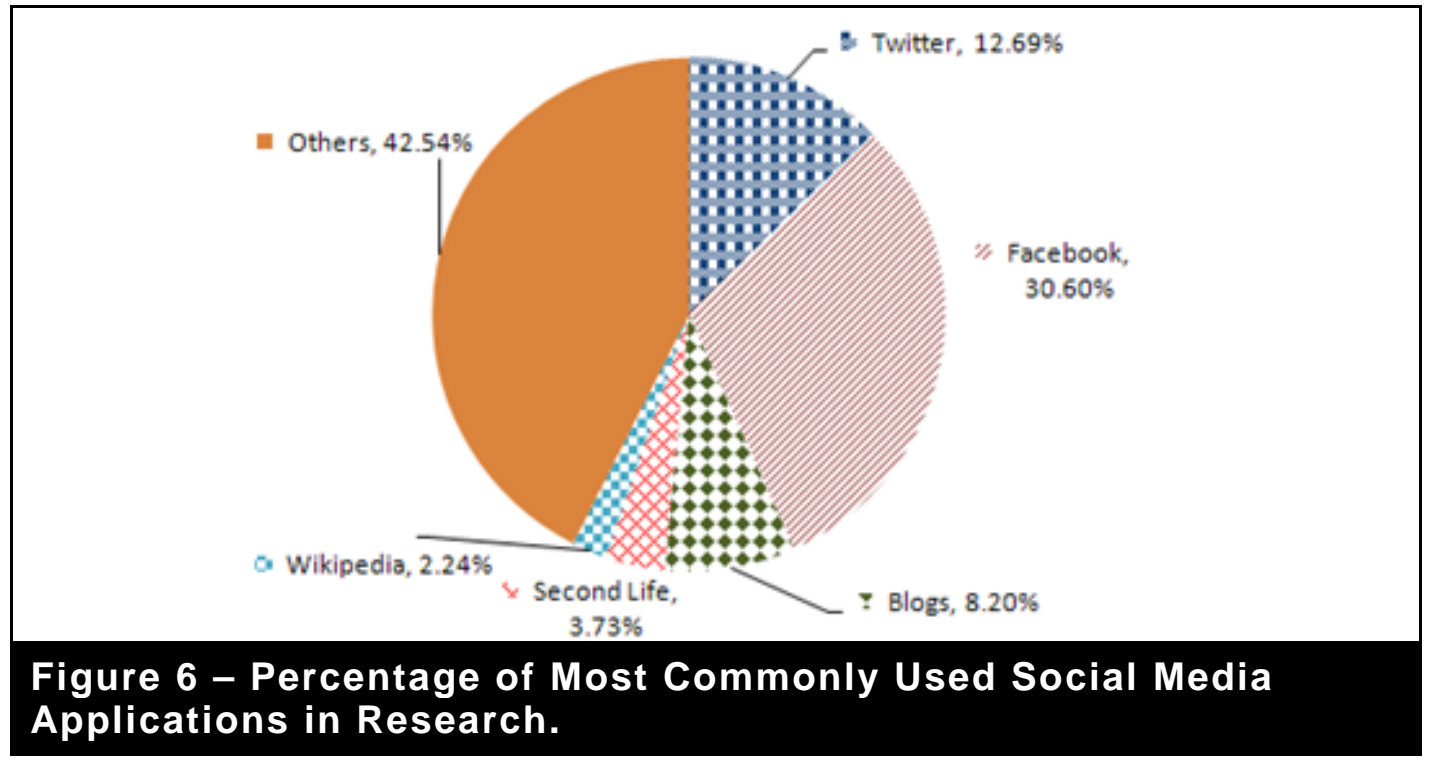

\section{Discussion}

According to Greenburg (1991) building and maintaining a reference collection of relevant literature is a significant part of any new research venture. The analysis of the 194 papers in this study presents some interesting insights into the current literature on social media research. Research papers published during January 2009 to January 2013 were searched and analysed against the criteria set by this research. In context of social media research, we found 27 papers published in 2007, with the vast majority of these papers published in conference proceedings. With the continuous increase in publication in subsequent years, culminating in 89 papers published in 2012. Overall, the publications during 2009 to 2013 are predominantly in conference proceedings reflecting the emerging nature of the field of social media. Conferences offer good opportunities to explore new ideas and share work with colleagues across the discipline. Publication turn-around is faster than with the major journals and proceedings offer opportunities to get emerging work into the public domain as it evolves and develops. This quick turnaround fits the fast moving environment of social media and the sense of urgency in arriving at some understanding of what this field means for both theory and practice. Consequently, we have seen 25 conference papers as compared to only 2 journal papers during the first (i.e. 2009) of the four years covered in this study (see Table 2 for more details). However, in the following years, the proportion of research papers published in various journals was greater than the conference papers. We have also found that social media research has employed statistical data analysis more frequently than non-statistical data analysis. This trend depicts the intention to quantify 
data and generalize results from a sample to the population of interest. In the context of background paradigm, the majority of the examined social media research has used positivist rather than interpretive paradigm. The trend for data driven research highlights the stage of infancy in this research field where most efforts are made in reporting on the use of social media in particular domains rather than developing a generalizable framework, model or theory regarding social media usage. As ideas evolve and develop and theories are proposed or extended, we expect to see a greater emphasis on journal publications where more in-depth theory driven studies will be published. The analysis of 194 research papers reported in this study reveals that there are only 68 (out of the total 194 articles) theory driven papers over the four year period covered. An interesting aspect of the use of theory in these studies is the fact that there is a very wide range of existing theories that have been used. 43 different theories in 66 theory driven papers indicate an extensive search is underway to find some theoretical bases for social media research. Indeed, in our own research we have struggled to find existing theories that allow for an in-depth analysis of social media activity in any substantial way. Social capital theory (Preece 2000; Preece 2001) and the technology acceptance model (Davis 1989) are the two most commonly occurring theories in these papers. This is somewhat deceptive as social capital theory is often used ineffectually in IS and TAM has been found to be less than useful for studying social media (Alam et al. 2012). It is to be hoped that theory driven research in this area will identify theories that can be used to contribute significantly to building a body of rigorous and substantial research.

A feature of interest to researchers in this area lies in the identification of popular social media applications in various studies. We found Facebook to be the most popular tool, featuring as the research focus in nearly a third of the total number of articles included in this study. Moreover, we have observed continuous increase in the number of research articles using Facebook over the four year period covered in this study. This is perhaps not surprising given the vast membership, ubiquity and interactivity of the platform. Similar to Facebook, another single social media application that stands out from the data analysis is Twitter. We have found 24 research papers that examined various aspects of Twitter and its value in various domains. Other than Facebook and Twitter, number of other social media applications such as Wikipedia, blogs, LinkedIn, Taobao.com, Paipai.com, MMOG Ocean Control, Habbo, Vkintakte.ru, Ireko, 1187.com, and Bittorrent has been used in 111 research articles. However, these applications either have not been used very often or generalized as 'social media' or 'social networking' and hence categorized as a special category called 'OT (others)' in this study (see Table 2 below). This study also found the lack of some specific disciplines or areas for social media research. In fact the role of social media has been examined in a huge range of areas that shows the versatility and application of social media in number of areas such as marketing, collaboration, sense-making, politics and of course socialization. 


\begin{tabular}{|c|c|c|c|c|c|c|}
\hline Year & $\begin{array}{l}\text { Papers } \\
\text { Published }\end{array}$ & $\begin{array}{l}\text { Publication } \\
\text { Type }\end{array}$ & $\begin{array}{l}\text { Research } \\
\text { Method }\end{array}$ & $\begin{array}{l}\text { Background } \\
\text { Paradigm }\end{array}$ & $\begin{array}{l}\text { Data I } \\
\text { theory } \\
\text { Driven }\end{array}$ & $\begin{array}{l}\text { Social media } \\
\text { Application }\end{array}$ \\
\hline \multirow{3}{*}{2009} & \multirow{3}{*}{27} & $C A=25$ & $\mathrm{QL}=12^{*}$ & $\mathrm{PT}=19$ & $\mathrm{DD}=17$ & $\mathrm{FB}=9$ \\
\hline & & \multirow{2}{*}{$J A=2$} & \multirow{2}{*}{$\mathrm{QT}=19 *$} & \multirow{2}{*}{$\mathrm{IT}=8$} & \multirow{2}{*}{$\mathrm{TD}=10$} & $\mathrm{TT}=4$ \\
\hline & & & & & & $\mathrm{OT}=14$ \\
\hline \multirow{3}{*}{2010} & \multirow{3}{*}{35} & $C A=28$ & $\mathrm{QL}=17^{*}$ & $\mathrm{PT}=24$ & $\mathrm{DD}=26$ & $F B=14$ \\
\hline & & \multirow{2}{*}{$J A=7$} & \multirow{2}{*}{$\mathrm{QT}=23^{*}$} & \multirow{2}{*}{$\mathrm{IT}=11$} & \multirow{2}{*}{$\mathrm{TD}=9$} & $\mathrm{TT}=5$ \\
\hline & & & & & & OT $=16$ \\
\hline \multirow{3}{*}{2011} & \multirow{3}{*}{43} & $C A=39$ & $\mathrm{QL}=24^{*}$ & $\mathrm{PT}=35$ & $\mathrm{DD}=29$ & $\mathrm{FB}=16$ \\
\hline & & \multirow{2}{*}{$J A=4$} & \multirow{2}{*}{$\mathrm{QT}=32^{*}$} & \multirow{2}{*}{$\mathrm{IT}=8$} & \multirow{2}{*}{$\mathrm{TD}=14$} & $\mathrm{TT}=6$ \\
\hline & & & & & & OT $=21$ \\
\hline \multirow{3}{*}{2012} & \multirow{3}{*}{89} & $C A=76$ & $\mathrm{QL}=39^{*}$ & $\mathrm{PT}=61$ & $\mathrm{DD}=54$ & $\mathrm{FB}=20$ \\
\hline & & \multirow{2}{*}{$J A=13$} & \multirow{2}{*}{$\mathrm{QT}=55^{*}$} & \multirow{2}{*}{$\mathrm{IT}=28$} & \multirow{2}{*}{$\mathrm{TD}=35$} & $\mathrm{TT}=9$ \\
\hline & & & & & & OT $=60$ \\
\hline Total & 194 & 194 & $221^{*}$ & 194 & 194 & 194 \\
\hline
\end{tabular}

$\mathbf{C A}=$ Conference articles, $\mathbf{J A}=$ Journal articles, $\mathbf{Q} \mathbf{L}=$ Qualitative, $\mathbf{Q} \boldsymbol{T}=$ Quantitative, $\boldsymbol{P T}=$ Positivist, $\mathbf{I T}=\mathbf{I n t e r p r e t i v e ,} \mathbf{T D}$ $=$ Theory driven, $\mathbf{D D}=$ Data driven, $\mathbf{F B}=$ Facebook, $\mathbf{T} \mathbf{T}=$ Twitter, $\mathbf{O T}=$ Others, *=articles used mixed-method approach

\section{Conclusions}

This study presents a review of academic literature to highlight the current status of social media research. We have drawn a general picture of the latest trends in social media research and created a database of the academic literature on social media from January 2009 to January 2013 by classification and statistical analysis. The study highlights the strong growth in social media literature in recent years, particularly in the latter part of the study where a $4 \%$ (approximately) annual increase in published literature from 2009 to 2011 almost increased by $20 \%$ in 2012 . There is little doubt that social media has become a 'hot' research area in the past few years and the rise in the recent publication rates foreshadows a substantial development in research and published literature on social media. While the literature in this period is predominantly from conference proceedings we anticipate that, with growing maturity of the field, more papers will appear in established journals as theory driven research becomes more widespread. We believe that the predominance of positivist studies will be tempered with more interpretive and perhaps critical research, as the need for more extensive in-depth exploration of the phenomenon is identified particularly in the organisational context.

There are a few limitations to the study presented in this paper. Access to databases limited the search to some degree, while the criteria used to determine the inclusion of a particular article further reduced the number of articles that qualified for this study. A further limitation of this study is the time period. Analysis presented in this study contains articles published between January 2009 and January 2013, which is not an extensive period for an exhaustive review. Nevertheless, this is a field of research that remains in its infancy 
and the period of study reflects a time span within which social media research began to be published in AIS conferences and IS journals. A limitation is imposed by the boundary of the discipline. Social media is a field of research in a very broad array of disciplines, from sociology, to media and marketing, but we have confined our review to IS. This approach may have eliminated some studies that are of significant interest to our discipline, but the scope of research is potentially too vast for a study that contributes to one discipline area.

\section{Directions for Future Research}

One of the greatest challenges in social media research is to bridge the gap between practitioners and researchers. Our analysis of literature indicates that the majority of research studies report on the usage of social media tools/applications in a particular area or domain. As the technology matures over time, we should see more attention being paid to less developed research areas, such as the need for more rigorous theoretical underpinnings. Moreover, there is a need to provide useful guidelines for practitioners to inform the processes of social media design, development, implementation and evaluation. We anticipate that future research will address the above areas and attempt to answer the following research questions.

- What models and theories on social media design, implementation, and evaluation have been developed for practitioners?

- Does the research into social media meet the needs of practitioners and managers?

- What models, theories, concepts, frameworks, methods, techniques and tools are being applied in practice?

- Does the research into social media have rigorous theoretical underpinnings?

- Have we developed any comprehensive roadmap for detailed technical and economic decisions for practitioners to appropriate social media application/s for implementation?
- Have we developed any framework to study the economic performance of social media applications in terms of their 'cradle to grave' costs? This includes the costs of designing, developing, maintaining, controlling and updating the system.

- How do practitioners address issues of governance, control, privacy and security in the use of social media?

These are only some of the outstanding questions that have yet to be adequately addressed in the pursuit of practical and theoretical implications for social media research. This exciting and important area will continue to develop and challenge as a field of research for many years to come.

\section{References}

Alam, L. S., and Diamah, A. (2012). "Understanding user participation in Australian Government Tourism Facebook Page," in 23rd Australasian Conference on Information Systems: Geelong, Australia.

Blackshaw, P. (2006). "The consumergenerated surveillance culture."

Boyd, M. D., and Ellison, B. N. 2008. "Social Network Sites: Definition, History, and Scholarship," Journal of Computer-Mediated Communication (13), pp 210-230.

Bryman, A. (2001). Social Research Methods, (Oxford University Press): Oxford

Chen, W., and Hirschheim, R. (2004). "A Paradigmatic and Methodological Examination of Information Systems Research From 1991 to 2001," Information Systems Journal (14), pp 197-235.

Curtis, A. (2013). "The Brief History of Social Media," in Where people interact freely, sharing and discussing information about their lives. 
Davis, F. D. (1989). "Perceived usefulness, perceived ease of use, and user acceptance of information technology," MIS Quarterly (13:3), pp 319-339.

Dibbern, J., Goles, T., Hirschheim, R., and Jayatilaka, B. (2004). "Information Systems Outsourcing: A Survey and Analysis of the Literature," The DATA BASE for Advances in Information Systems (35:4).

Feller, J., Finnegan, P., Kelly, D., and MacNamara, M. (2006). "Developing Open Source Software: A Community-Based Analysis of Research," in Social Inclusion: Societal and Organizational Implications for Information Systems, E. Trauth, D. Howcroft, T. Butler, B. Fitzgerald and J. DeGross (eds.), Springer US, pp. 261-278.

Greenburg, S. (1991). "An annotated bibliography of computer supported cooperative work," Special issue: Computer supported cooperative work. ACM SIGCHI Bulletin (23:3), pp 29-62.

Kaplan, M. A., and Haenlein, M. (2010). "User of the World, Unite! The challenges and opportunities of Social Media," Business Horizons (53), pp 59-68.

Liu, F., and Myers, D. M. (2011). "An Analysis of the AIS Basket of Top Journals," Journal of Systems and Information Technology (13:1), pp 524.

Mingers, J. (2003). "The Paucity of Multimethod Research: A Review of the Infromation Systems Literature," Infromation Systems Journal (13), pp 233-249.

Myers, M. D., and Klein, H. K. (2011). "A set of principles for conducting critical research in information systems," MIS Q. (35:1), pp 17-36.
Ngai, E. W. T., Moon, K. L. K., Riggins, J. F., and Yi, Y. C. (2008). "RFID Research: An Academic Literature Review (1995-2005) and Future Research Directions," International Journal of Production Economics (112), pp 510520.

Preece, J. (2000). Online communities. Designing usability, supporting sociability, (John Wiley \& Sons: New York.

Preece, J. (2001). "Sociability and usability: Twenty years of chatting online," behavior and Information Technology (20:5), pp 347-356.

Safko, L. (2010). The Social Media Bible: Tactics, Tools, and Strategies for Business Success, (John Wiley \& Sons.

Scornavacca, E., Barnes, S., and Huff, S. Year. "Mobile Business Research, 2000-2004: Emergence, Current status, and Future Opportunities," European Conference on Information Systems (ECIS), Regensburg, Germany,( 2005).

Walsham, G. (1995). "The Emergence of Interpretivism in IS Research," Information Systems Research (6:4).

Webster, J., and Watson, R. (2002). " Analysing the Past to Prepare for the Future: Writing a Literature Review," MISQ (26:2), pp xiii-xxiii.

Xianga, Z., and Gretzelb, U. (2010). "Role of Social Media in Online Travel Information Search," Tourism Management (31:2), pp 179-188.

Yin, R. K. (1994). Case Study Research Design and Methods, (Second ed.) SAGE Publications Ltd.: London. 


\section{About Authors}

Ashir Ahmed is a lecturer of Information Systems at Swinburne University of Technology, Australia. He earned his PhD degree in information systems from Monash University, Australia. His research interests focus on the role of social media in various context including Disaster Management and Small and Medium Enterprises (SMEs). He has published his research in the area of technology adoption (such as Radio Frequency Identification) in Disaster Management that appeared in International Conference on Information Systems (ICIS), European Conference on Information Systems (ECIS), Hawaii International Conference on System Sciences (HICSS) and Pacific Asia Conference on Information Systems (PACIS).

Helana Scheepers is an Associate Professor in the Faculty of Information and Communication Technologies at Swinburne University, Australia. She received her Ph.D. from Aalborg University in Denmark in 2000. She has worked in academic institutions in South Africa, Denmark, Canada and Australia. Her research interests include the development, management and adoption of information technology by large and small organisations. She has studied the use of mobile technology by organisations identifying how the private use of mobile technology impact on the organisational use. Her interest in the last two years has been specifically in the areas of the adoption of electronic government and social media technology by organisations. She has published in journals such as the European Journal of Information Systems, Information Systems Frontiers and Communications of the Association of Information Systems
Rosemary Stockdale is an Associate Professor in the Faculty of Information and Communication Technology at Swinburne University of Technology in Melbourne, Australia. She has a PhD in Information Systems from Edith Cowan University, Perth. She teaches IT for Non-IT Managers at Masters Level and Information Systems Management to undergraduate students. Her current research interests include online communities, social computing and the use of social media inorganizations. Dr Stockdale has published over 70 journal and conference papers in a range of Information Systems journals and conferences including the European Journal of Operational Research, Information and Organization and the European and Australasian Conferences on Information Systems. 